\title{
Nonpalpable Testicular Masses-Should We Be Worried?
}

\author{
Hamid Abboudi ${ }^{1}$, Sachin Malde ${ }^{2}$, Ahmad Mchaourab ${ }^{1}$, Ben Eddy ${ }^{1}$, Nitin Shrotri $^{1}$ \\ ${ }^{1}$ Department of Urology, Kent and Canterbury Hospital, Canterbury, UK \\ ${ }^{2}$ Department of Urology, Medway Maritime Hospital, Gillingham, UK \\ Email: hamid.abboudi@doctors.org.uk
}

Received October 16, 2013; revised November 10, 2013; accepted November 17, 2013

Copyright @ 2013 Hamid Abboudi et al. This is an open access article distributed under the Creative Commons Attribution License, which permits unrestricted use, distribution, and reproduction in any medium, provided the original work is properly cited.

\begin{abstract}
Objective: To report our experience of a contemporary series of patients who underwent radical orchidectomy for non-palpable testicular masses, in order to comment on their malignant potential and identify any factors predictive of a malignant outcome. Materials and Methods: We reviewed the case-notes of patients who underwent radical inguinal orchidectomy over a 22-month period between January 2010 and October 2011. Results: A total of 71 patients were analysed, with a mean (range) age of 45 years (17 - 82). Overall, 41 (57.7\%) orchidectomies were malignant and 30 (42.3\%) were benign. There were 20 (28\%) non-palpable testicular masses found incidentally on ultrasound, and of these $40 \%$ were malignant and $60 \%$ were benign. In total 6 of these non-palpable lesions were $<1 \mathrm{~cm}$ in size, and of these $66.6 \%$ were malignant and $33.3 \%$ were benign. The majority of tumours were in patients under the age of 50 , but there was no correlation between the lesion size and the risk of a malignant outcome. Conclusion: In view of the significant rate of malignancy in non-palpable testicular masses we recommend surgical intervention over surveillance alone. However, as the majority of these lesions may eventually turn out to be benign, we suggest that testis-sparing surgery is the optimal approach, and should be performed in centres where the required radiological, histopathological, and surgical expertise exists.
\end{abstract}

Keywords: Biopsy; Neoplasms; Orchidectomy; Testis; Ultrasonography

\section{Introduction}

Radical orchidectomy through an inguinal approach is currently considered to be the gold-standard treatment for all testicular masses suspicious for malignancy [1]. This is based on historical data suggesting that $90 \%-95 \%$ of palpable testicular masses are malignant germ cell tumours [2]. However, several factors have led to this traditional and routine strategy being questioned in recent years. It is now recognised that a much higher proportion of radical orchidectomies ultimately reveal benign pathology and are therefore performed unnecessarily [3]. Furthermore, with the widespread use of high-resolution scrotal ultrasound for a variety of complaints, a greater number of incidental testicular lesions (as small as $1 \mathrm{~mm}$ ) are being increasingly identified. Although these lesions are typically hypoechoic, and therefore difficult to differentiate from seminomas, the rate of benign pathology in these non-palpable, incidentally-discovered lesions has been reported to be as high as $80 \%$ [4]. Clearly radical orchidectomy represents overtreatment for this group of men. In addition to this, there has been an increasing trend towards organ-sparing surgery for a number of other cancers, and positive data for testis-sparing surgery have accumulated more recently [4]. Preserved fertility, a reduced need for androgen substitution, and an improved health-related quality of life are potential benefits of this organ-sparing approach but this is still not widely practiced due to uncertainty regarding the malignant risk of these "incidentalomas".

The optimal management of these small, non-palpable testicular lesions is therefore controversial. Some advocate frozen-section analysis (FSA) and testis-sparing surgery whereas others recommend immediate radical orchidectomy, citing the inaccuracy of FSA and difficulty of intra-operative localisation of the tumour as reasons.

Although several case series have reported on the malignant risk of small, incidentally-detected testicular masses, results have been contradictory [5-14]. We report our experience in a contemporary series of patients who underwent radical orchidectomy for non-palpable testicular masses and comment on their malignant potential. 


\section{Materials and Methods}

We retrospectively reviewed the case-notes of all patients who underwent orchidectomy at our institution over a 22-month period between January 2010 and October 2011. Data was collected on patient age, presenting symptoms, clinical examination findings, indication for ultrasound scan, ultrasonic features, serum tumour markers, and final histological diagnosis.

Patients who underwent orchidectomy for testicular torsion, abscesses, or other benign conditions were excluded.

Data was analysed on Microsoft ${ }^{\mathrm{TM}}$ Office Excel 2007. The independent two-sample $t$-test was used to compare two groups of independent parametric numerical data, and the Mann Whitney test was used to compare nonparametric data, with a two-sided $P<0.05$ considered to indicate statistical significance.

\section{Results}

A total of 148 orchidectomies were performed over this time-period. Seventy-seven did not meet the study inclusion criteria (i.e. were not radical inguinal orchidectomies) and were therefore excluded, resulting in a total of 71 patients available for further analysis, with a mean (range) age of 45 years (17 - 82). Overall, 41 (57.7\%) radical orchidectomies ultimately revealed malignant pathology and 30 (42.3\%) were benign (Table 1).

There was a statistically significant difference in the mean age of those with malignant compared to benign lesions, with older patients more likely to have benign pathology. The mean (SD) age of those with malignant lesions was 40.9 (17.8) years and for benign lesions was $51.0(16.5)$ years $(P=0.01)$.

There were 20 (28\%) non-palpable testicular masses found on ultrasound, and of these 8 (40\%) were malignant and 12 (60\%) were benign (Table 2).

Table 1. Summary of final pathology of all radical orchidectomies.

\begin{tabular}{|c|c|}
\hline Pathology & Total number \\
\hline Malignant & 41 \\
\hline Seminoma & 21 \\
\hline Teratoma & 2 \\
\hline Mixed germ cell tumour & 10 \\
\hline B-cell lymphoma/leukaemia & 6 \\
\hline Leydig cell tumour & 1 \\
\hline Rhabdomyosarcoma & 1 \\
\hline Benign & 30 \\
\hline Epidermoid cyst & 8 \\
\hline Adenomatoid tumour & 1 \\
\hline Inflammation & 11 \\
\hline Haemorrhagic infarction & 4 \\
\hline Atrophy/fibrosis & 2 \\
\hline Benign paratesticular pseudocyst & 1 \\
\hline Normal & 3 \\
\hline
\end{tabular}

Table 2. Characteristics of patients with non-palpable testicular masses (malignant lesions highlighted in bold).

\begin{tabular}{|c|c|c|c|c|c|}
\hline Patient number & Age & Indication for ultrasound & Ultrasonic features & Size of lesion $(\mathrm{mm})$ & Final pathology \\
\hline 1 & 52 & Scrotal pain & Hypoechoic & $40 \times 27$ & Granulomatous orchitis \\
\hline 2 & 35 & Scrotal pain & Inflammation and infarction & N/A & Inflammation \\
\hline 4 & 44 & Haematospermia & Mixed echogenicity & $29 \times 23$ & Benign testicular cyst \\
\hline 5 & 72 & Scrotal swelling post-hernia repair & Mass containing debris & N/A & Haematoma \\
\hline 7 & 55 & Groin pain & Atrophic testis & N/A & Atrophy \\
\hline 8 & 63 & Scrotal pain & Hypoechoic & $6 \times 8$ & Inflammation \\
\hline 9 & 68 & Scrotal pain & Mixed echogenicity & $18 \times 12$ & Granulomatous orchitis \\
\hline 10 & 55 & $\begin{array}{c}\text { Retroperitoneal } \\
\text { lymphadenopathy on CT scan }\end{array}$ & Hypoechoic & 10 & Atrophy/fibrosis \\
\hline 11 & 34 & Scrotal pain & Heterogenous mass & 20 & Seminoma \\
\hline 13 & 56 & Scrotal pain & Complex mass & 11 & Normal \\
\hline 14 & 26 & Scrotal pain & Multiple echogenic lesions & 10 & Infarct \\
\hline 15 & 27 & Scrotal pain & Well-defined “onion-ring” appearance & 14 & Epidermoid cyst \\
\hline 16 & 44 & Scan done for inguinal hernia & Hypoechoic & $17 \times 12$ & Seminoma \\
\hline 17 & 30 & Scrotal pain & Hypoechoic & 10 & Seminoma \\
\hline 18 & 32 & Scrotal pain & Hypoechoic & $5 \times 7$ & Seminoma \\
\hline 19 & 34 & Scrotal pain & Multiple hypoechoic lesions & 17 & Seminoma \\
\hline 20 & 78 & Scrotal pain and swelling & Multiple hypoechoic lesions & 20 & B-cell lymphoma \\
\hline
\end{tabular}


Serum tumour markers were normal in all cases of non-palpable lesions apart from one (who was being investigated following a finding of retroperitoneal lymphadenopathy on CT).

\section{Stratification by age}

When this patient group with non-palpable masses was stratified by age, those with cancer were generally younger than those with benign disease (median 39 years vs. median 55 years). All germ cell tumours were diagnosed in patients under the age of 50, except one who had a seminoma in an atrophic testicle.

\section{Stratification by tumour diameter}

The overall mean tumour diameter for these non-palpable lesions was $1.4 \mathrm{~cm}$, with malignant lesions having a slightly smaller mean diameter than benign ones (1.3 $\mathrm{cm}$ v. $1.5 \mathrm{~cm})$, although this was not significant $(P=$ 0.64). Furthermore, when the size of each lesion was analysed as a proportion of the entire testicular size, there was no significant difference between benign and malignant pathologies (Table 3). The mean size of the mass in relation to the size of the testicle was $42.1 \%$ for malignant lesions and $42.3 \%$ for benign lesions $(P=0.98)$.

\section{Analysis of hypoechoic lesions}

Hypoechoic lesions are the ultrasonic hallmark of seminomatous tumours. There were a total of 6 hypoechoic, non-palpable lesions less than $1 \mathrm{~cm}$ (Table 4). Of these, $4(66.6 \%)$ were malignant and 2 (33.3\%) were benign. None of these patients had raised serum tumour markers. Three out of 4 patients (75\%) with malignant tumours were under 50 , whilst of those over 50 with hypoechoic lesions $<1 \mathrm{~cm}$ in size only 1 out of 3 (33.3\%) had a germ cell tumour, and this was in an atrophic testicle.

\section{Discussion}

Testis-sparing surgery is currently only recommended for highly-selected patients-those with synchronous bilateral testicular tumours, metachronous tumours, or tumours in a solitary testicle. Furthermore, it is recommended that patients have sufficient pre-operative serum testosterone levels, and that the tumour volume is less than $30 \%$ of the total testicular volume in order to pursue this more conservative surgical approach [1].
For all other patients who do not meet these criteria, radical inguinal orchidectomy remains the standard of care. The case for patients with equivocal lesions and a normal contralateral testis, however, is less clear-cut. High-resolution ultrasound can detect intra-testicular lesions as small as $1 \mathrm{~mm}$, and therefore a greater number of non-palpable, incidental lesions are being identified. Options for further management of this group include ultrasonic surveillance, excision biopsy and FSA, partial orchidectomy, or radical orchidectomy. The main factor affecting the choice of approach is the perceived malignant risk of the testicular lesion. A number of small case-series have attempted to determine the malignant potential of non-palpable testicular lesions but results have been contradictory.

In this study, we report a high overall rate of benign pathology following radical orchidectomy which may be related to the greater use of scrotal ultrasound for a variety of complaints. The use of more conservative surgical options could have potentially prevented $42.3 \%$ of patients from having an orchidectomy. Non-palpable lesions accounted for a significant proportion of all tes-

Table 3. Table showing proportion of testicle taken up by mass lesion (malignant lesions highlighted in bold).

\begin{tabular}{ccc}
\hline Size of lesion (mm) & Size of testis $(\mathbf{m m})$ & $\begin{array}{c}\text { Proportion of testis } \\
\text { taken up by lesion }(\mathbf{\%})\end{array}$ \\
\hline $\mathbf{4 0}$ & $\mathbf{5 5}$ & $\mathbf{7 2 . 7}$ \\
$\mathbf{3}$ & $\mathbf{4 0}$ & $\mathbf{7 . 5}$ \\
$\mathbf{2 9}$ & $\mathbf{4 5}$ & $\mathbf{6 4 . 4}$ \\
$\mathbf{1 1}$ & $\mathbf{2 6}$ & $\mathbf{4 2 . 3}$ \\
$\mathbf{1 0}$ & $\mathbf{5 0}$ & $\mathbf{2 0 . 0}$ \\
$\mathbf{1 4}$ & $\mathbf{3 9}$ & $\mathbf{3 5 . 9}$ \\
$\mathbf{8}$ & $\mathbf{3 5}$ & $\mathbf{2 2 . 9}$ \\
$\mathbf{1 8}$ & $\mathbf{3 2}$ & $\mathbf{5 6 . 3}$ \\
$\mathbf{1 0}$ & $\mathbf{1 7}$ & $\mathbf{5 8 . 8}$ \\
20 & 30 & 66.7 \\
13 & 26 & 50.0 \\
17 & 38 & 44.7 \\
10 & 35 & 28.6 \\
6 & 37 & 16.2 \\
17 & 41 & 41.5 \\
20 & 42 & 47.6 \\
\hline
\end{tabular}

Table 4. Characteristics of patients with small $(\leq 1 \mathrm{~cm})$, non-palpable, hypoechoic lesions (malignant lesions highlighted in bold).

\begin{tabular}{cccccc}
\hline Patient number & Age & Reason for presentation & Examination findings & Ultrasound findings & Final pathology \\
\hline $\mathbf{1}$ & $\mathbf{2 4}$ & Unknown & No mass palpable & $\mathbf{2}$ hypoechoic lesions-12 and $\mathbf{5}$ mm & Mixed germ cell tumour \\
$\mathbf{2}$ & $\mathbf{5 2}$ & Small testicle & $\begin{array}{c}\text { Atrophic testicle, } \\
\text { no mass palpable }\end{array}$ & $\mathbf{6} \times \mathbf{5} \mathbf{~ m m ~ h y p o e c h o i c ~ l e s i o n ~}$ & Seminoma \\
$\mathbf{3}$ & $\mathbf{3 0}$ & Testicular pain & No mass palpable & $\mathbf{1 0} \mathbf{~ m m}$ hypoechoic lesion & Seminoma \\
$\mathbf{4}$ & $\mathbf{3 2}$ & Testicular pain & No mass palpable & $\mathbf{5} \times \mathbf{7} \mathbf{~ m m ~ h y p o e c h o i c ~ l e s i o n ~}$ & Seminoma \\
5 & 63 & Enlarged testicle & No mass palpable & $8 \times 6 \mathrm{~mm}$ hypoechoic lesion & Inflammation \\
6 & 55 & $\begin{array}{c}\text { Retroperitoneal } \\
\text { lymphadenopathy on CT }\end{array}$ & No mass palpable & 10 mm hypoechoic lesion & Atrophy/fibrosis \\
\hline
\end{tabular}


ticular masses in this series, and our rate of malignant pathology of $40 \%$ is higher than that of other published reports. This may be due to the fact these were not all "incidentally" found lesions as some were being investigated for retroperitoneal masses, and so the malignancy rate would be expected to be higher.

In an early study of incidentally-discovered, non-palpable testicular masses, Horstman et al. [8] found a $22.2 \%$ rate of malignancy. The mean tumour diameter of malignant lesions in that study was comparable to our series. A more recent study by Sheynkin et al. [15] confirmed these results, with only 2 of 8 non-palpable testicular masses proving to be malignant following radical orchidectomy. Another study by Leroy et al. [16] provided further support for the low rate of malignant pathology in small, non-palpable testicular masses by demonstrating a $27 \%$ rate of malignancy in lesions with a mean diameter of $7.5 \mathrm{~mm}$. These reported high rates of benign pathology are for lesions with a mean size of $1 \mathrm{~cm}$ or less, although our study shows that the chance of benign pathology is still significant even with lesions up to $2 \mathrm{~cm}$, and this has been confirmed by an earlier study [17].

However, other studies have reported contradictory results. Comiter et al. [9] found a high rate of malignant pathology (73\%) amongst non-palpable testicular masses, although this study included patients with retroperitoneal or neck masses in whom testicular ultrasound was performed in order to identify a potential primary tumour, and therefore this higher rate of malignancy would be expected. Hindley et al. [18] reported 3 out of 4 non-palpable lesions to be seminomatous, whilst Avci et al. [14] reported 8 out of 9 non-palpable masses to be malignant.

In terms of being able to predict a malignant outcome, we found no correlation between the diameter of the lesion, the size of the lesion in proportion to the size of the testis, and final pathology. However, age appeared to be a good predictor of malignant germ cell tumour, as the majority occurred in those under the age of 50. In fact, there was only 1 case of seminoma in a patient over the age of 50, and this patient had an atrophic testis. Therefore, if a non-palpable lesion is found in a patient over the age of 50, in the absence of risk factors for germ cell tumours (cryptorchidism, atrophic testis), a conservative surgical approach or ultrasonic surveillance represent valid management options after careful patient counselling.

Various alternative options have been studied in an attempt to determine the malignant potential of these lesions prior to radical surgery. The use of magnetic resonance imaging (MRI) has been supported by some authors as a means to improve the sensitivity and specificity in diagnosing malignant lesions [19]. MRI can be useful as a problem-solving tool in cases where ultrasound is equivocal, and can help to identify benign pa- thology such as orchitis, haemorrhage, infarction, and fibrosis. In one study of 36 intratesticular lesions, MRI correctly identified 28 out of 28 lesions as being malignant and 7 out of 8 lesions as being benign (sensitivity $100 \%$, specificity $87.5 \%$ ) [20]. However, this study included patients with large (mean tumour diameter 5.2 $\mathrm{cm}$ ), palpable lesions. Its utility in patients with small, non-palpable lesions remains to be determined, and it is therefore unlikely to replace ultrasonography as a firstline investigation.

Excision biopsy and FSA has taken on a greater role in a number of centres, the main aim being the identification of malignant lesions and confirmation of adequate margin excision. If malignancy is confirmed the surgeon can proceed with radical orchidectomy. However, if the lesion is shown to be benign the remnant testis can be returned to the scrotum, thereby preventing an unnecessary orchidectomy. In specialist units with the appropriate histological expertise this approach has been shown to have excellent results. FSA reported a correct diagnosis in all 26 cases described by Tokuic et al. [21] and in the 317 malignant testicular tumours reported by Elert et al. [22] FSA confirmed the correct diagnosis in all cases. However, this experience is not universal [13] and depends on the expertise of the pathologist and adequacy of the frozen section. Furthermore, there remain concerns regarding the possibility of missing a multifocal tumour or intra-tubular germ cell neoplasia (ITGCN), with some data suggesting that additional tumours are found distant to the index mass in up to $63 \%$ of men considered suitable for testis-sparing surgery [23]. Patients should be counselled regarding the need for delayed orchidectomy (if the permanent section demonstrates malignancy), or adjuvant radiotherapy for ITGCN. In this respect, however, testis-sparing surgery has been shown not to compromise oncological safety. In the largest series to date, the German testicular cancer study group treated 101 men with bilateral tumours or tumours in a solitary testicle with testis-sparing surgery. All patients with ITGCN were offered post-operative radiotherapy. Cancer-specific survival after a mean of 80-month follow-up was excellent (100 of 101), with local recurrence in only 6 of 101, 4 of whom had refused adjuvant radiotherapy [24].

There are a number of benefits to this organ-sparing approach. Firstly, it prevents the overtreatment of the majority of men whose non-palpable lesions are benign. There is some evidence to suggest that loss of a testicle impairs fertility, endocrine function, and has a negative impact on psychosocial well-being [4]. Preserving as much testicular parenchyma as possible is therefore beneficial, providing oncological control is not jeopardised. In the series by Heidenreich et al. [24], only 10 of 101 men treated with testis-sparing developed new-onset hypogonadism at a mean of 80-months follow-up. Further- 
more, if a man wishes to father children, adjuvant radiotherapy after testis-sparing surgery can be deferred until this has occurred, although close ultrasonic surveillance of the remnant testis is required.

\section{Conclusion}

In conclusion, our series confirms previous results showing that the majority of non-palpable testicular masses less than $2 \mathrm{~cm}$ in diameter are benign lesions. In view of the possible significant risk of malignancy, however, we recommend that all such lesions are managed surgically, with excision biopsy, frozen-section analysis and testissparing surgery the optimal approach. If the lesion proves to be benign, the patient is spared the overtreatment of orchidectomy with its negative impact on endocrine and exocrine function and psychosocial well-being. It is important that this approach be undertaken in centres with specialist histopathological and surgical expertise. In patients over the age of 50 without any risk factors for germ-cell tumours, the risk of malignancy appears low and a more conservative approach could be taken. In any case, patients should be counselled that radical orchidectomy remains the standard of care for oncological control, and if the testis-sparing approach is undertaken then close surveillance will be required for many years.

\section{REFERENCES}

[1] P. Albers, W. Albrecht, F. Algaba, C. Bokemeyer, G. CohnCedermark, K. Fizazi, et al., European Association of Urology Guidelines on Testicular Cancer, 2012. http://www.uroweb.org/fileadmin/tx_eauguidelines/2012/ Full/Testis_Cancer.pdf

[2] J. P. Richie, "Detection and Treatment of Testicular Cancer,” CA: A Cancer Journal for Clinicians, Vol. 43, No. 3, 1993, pp. 151-175. http://dx.doi.org/10.3322/canjclin.43.3.151

[3] A. Heidenreich and M. Angerer-Shpilenya, "Organ-Preserving Surgery for Testicular Tumours,” BJU International, Vol. 109, No. 3, 2012, pp. 474-490. http://dx.doi.org/10.1111/j.1464-410X.2011.10913.x

[4] G. Giannarini, K. P. Dieckmann, P. Albers, A. Heidenreich and G. Pizzocaro, "Organ-Sparing Surgery for Adult Testicular Tumours: A Systematic Review of the Literature,” European Urology, Vol. 57, No. 5, 2010, pp. 780790. http://dx.doi.org/10.1016/j.eururo.2010.01.014

[5] Z. Csapo, C. Bornhof and J. Giedl, "Impalpable Testicular Tumors Diagnosed by Scrotal Ultrasonography," Urology, Vol. 32, No. 6, 1988, pp. 549-552. http://dx.doi.org/10.1016/S0090-4295(98)90043-7

[6] M. B. Buckspan, P. G. Klotz, M. Goldfinger, S. Stoll and B. Fernandes, "Intraoperative Ultrasound in the Conservative Resection of Testicular Neoplasms," Journal of Urology, Vol. 141, No. 2, 1989, pp. 326-327.

[7] D. Corrie, E. J. Mueller and I. M. Thompson, "Management of Ultrasonically Detected Nonpalpable Testis Mas- ses,” Urology, Vol. 38, No. 5, 1991, pp. 429-431. http://dx.doi.org/10.1016/0090-4295(91)80231-U

[8] W. G. Horstman, M. M. Haluszka and T. K. Burkhard, "Management of Testicular Masses Incidentally Discovered by Ultrasound,” Journal of Urology, Vol. 151, No. 5, 1994, pp. 1263-1265.

[9] C. V. Comiter, C. J. Benson, C. C. Capelouto, P. Kantoff, L. Shulman and J. P. Richie, "Nonpalpable Intratesticular Masses Detected Sonographically,” Journal of Urology, Vol. 154, No. 4, 1995, pp. 1367-1369.

http://dx.doi.org/10.1016/S0022-5347(01)66865-4

[10] C. V. Hopps and M. Goldstein, "Ultrasound Guided Needle Localization and Microsurgical Exploration for Incidental Nonpalpable Testicular Tumors,” Journal of Urology, Vol. 168, No. 3, 2002, pp. 1084-1087. http://dx.doi.org/10.1016/S0022-5347(05)64580-6

[11] L. Carmignani, F. Gadd, G. Gazzano, F. Nerva, M. Mancini, M. Ferruti, et al., "High Incidence of Benign Testicular Neoplasms Diagnosed by Ultrasound,” Journal of Urology, Vol. 170, No. 5, 2003, pp. 1783-1786. http://dx.doi.org/10.1097/01.ju.0000092066.01699.90

[12] T. Muller, C. Gozzi, T. Akkad, L. Pallwein, G. Bartsch and H. Steiner, "Management of Incidental Impalpable Intratesticular Masses of < or $=5 \mathrm{~mm}$ in Diameter," BJU International, Vol. 98, No. 5, 2006, pp. 1001-1004. http://dx.doi.org/10.1111/j.1464-410X.2006.06485.x

[13] T. M. Powell and T. H. Tarter, "Management of Nonpalpable Incidental Testicular Masses," Journal of Urology, Vol. 176, No. 1, 2006, pp. 96-98. http://dx.doi.org/10.1016/S0022-5347(06)00496-4

[14] A. Avci, B. Erol, C. Eken and Y. Ozgok, "Nine Cases of Nonpalpable Testicular Mass: An Incidental Finding in a Large Scale Ultrasonography Survey,” International Journal of Urology, Vol. 15, No. 9, 2008, pp. 833-836. http://dx.doi.org/10.1111/j.1442-2042.2008.02120.x

[15] Y. R. Sheynkin, T. Sukkarieh, M. Lipke, H. L. Cohen and D. A. Schulsinger, "Management of Nonpalpable Testicular Tumors,” Urology, Vol. 63, No. 6, 2004, pp. 11631167. http://dx.doi.org/10.1016/j.urology.2003.12.054

[16] X. Leroy, J. M. Rigot, S. Aubert, C. Ballereau and B. Gosselin, "Value of Frozen Section Examination for the Management of Nonpalpable Incidental Testicular Tumors," European Urology, Vol. 44, No. 4, 2003, pp. 458-460. http://dx.doi.org/10.1016/S0302-2838(03)00316-6

[17] L. Carmignani, A. Morabito, F. Gadda, G. Bozzini, F. Rocco and G. M. Colpi, "Prognostic Parameters in Adult Impalpable Ultrasonographic Lesions of the Testicle,” Journal of Urology, Vol. 174, No. 3, 2005, pp. 1035-1038. http://dx.doi.org/10.1097/01.ju.0000170236.01129.d4

[18] R. G. Hindley, A. Chandra, A. Saunders and T. S. O’Brien, "Impalpable Testis Cancer," BJU International, Vol. 92, No. 6, 2003, pp. 572-574. http://dx.doi.org/10.1046/j.1464-410X.2003.04432.x

[19] R. Segal, H. Luka, L. H. Klotz, A. Eady, N. Bestic and M. Johnston, "Surveillance Programs for Early Stage NonSeminomatous Testicular Cancer: A Practice Guideline," The Canadian Journal of Urology, Vol. 8, No. 1, 2001, pp. 1184-1192.

[20] A. C. Tsili, M. I. Argyropoulou, D. Giannakis, N. Sofi- 
kitis and K. Tsampoulas, "MRI in the Characterization and Local Staging of Testicular Neoplasms," American Journal of Roentgenology, Vol. 194, No. 3, 2010, pp. 682-689. http://dx.doi.org/10.2214/AJR.09.3256

[21] R. Tokuc, W. Sakr, J. E. Pontes and G. P. Haas, “Accuracy of Frozen Section Examination of Testicular Tumors," Urology, Vol. 40, No. 6, 1992, pp. 512-516. http://dx.doi.org/10.1016/0090-4295(92)90405-L

[22] A. Elert, P. Olbert, A. Hegele, P. Barth, R. Hofmann and A. Heidenreich, "Accuracy of Frozen Section Examination of Testicular Tumors of Uncertain Origin,” European
Urology, Vol. 41, No. 3, 2002, pp. 290-293. http://dx.doi.org/10.1016/S0302-2838(02)00004-0

[23] Y. Ehrlich, M. Konichezky, O. Yossepowitch and J. Baniel, "Multifocality in Testicular Germ Cell Tumors," Journal of Urology, Vol. 181, 2009, pp. 1114-1119. http://dx.doi.org/10.1016/j.juro.2008.11.025

[24] A. Heidenreich, P. Albers and S. Krege, "Management of Bilateral Testicular Germ Cell Tumours-Experience of the German Testicular Cancer Study Group (GTCSG)," European Urology Supplements, Vol. 5, No. 2, 2006, p. 97. http://dx.doi.org/10.1016/S1569-9056(06)60305-9 